\title{
Decrease of Hospitalizations and Length of Hospital Stay in Patients with Schizophrenia Spectrum Disorders or Bipolar Disorder Treated in a Mobile Mental Health Service in Insular Greece
}

\author{
Aikaterini Garbi * ${ }^{\mathbb{D}}$, Ioannis Tiniakos, Zacharenia Mikelatou and Ioannis Drakatos \\ METAVASI, MMHU-KZI Vourvachi 6A, 28100 Argostoli, Kefalonia, Greece; ioannis_tiniakos@metavasi.gr (I.T.); \\ zacharenia_mikelatou@metavasi.gr (Z.M.); ioannis_drakatos@metavasi.gr (I.D.) \\ * Correspondence: katerina_garbi@metavasi.gr; Tel.: +30-26710-24437
}

\section{check for}

updates

Citation: Garbi, A.; Tiniakos, I.; Mikelatou, Z.; Drakatos, I. Decrease of Hospitalizations and Length of Hospital Stay in Patients with Schizophrenia Spectrum Disorders or Bipolar Disorder Treated in a Mobile Mental Health Service in Insular Greece. Psych 2021, 3, 780-791. https://doi.org/10.3390/ psych3040049

Academic Editor: Mosad Zineldin

Received: 29 October 2021

Accepted: 2 December 2021

Published: 4 December 2021

Publisher's Note: MDPI stays neutral with regard to jurisdictional claims in published maps and institutional affiliations.

Copyright: (c) 2021 by the authors. Licensee MDPI, Basel, Switzerland. This article is an open access article distributed under the terms and conditions of the Creative Commons Attribution (CC BY) license (https:/ / creativecommons.org/licenses/by/ $4.0 /)$.

\begin{abstract}
In recent years serious mental health issues, such as schizophrenia spectrum disorders and bipolar disorder, have been treated in the community by community-based mental health services. In the present study our goal was to estimate the modification in the number of hospitalizations and duration of admissions in either psychotic patients or patients with bipolar disorder, treated by a Mobile Mental Health Unit in the islands of Kefalonia, Zakynthos and Ithaca (MMHU-KZI). Data were collected from a total of 108 patients with schizophrenia spectrum disorders and bipolar disorder. For each patient comparison was made for the same time interval prior and after engagement to treatment with the MMHU-KZI and not for the total hospitalizations that patients had in their history. There was a statistically significant reduction $(45.9 \%)$ in hospitalizations after treatment engagement with the MMHU-KZI, as the Wilcoxon signed ranks test indicated. Furthermore, a major decrease $(54.5 \%)$ of hospitalization days was noted after treatment engagement with the unit. This pattern of mental health provision may be beneficial for the reduction of the number and duration of psychiatric hospitalizations. Despite the beneficial contribution of community-based mental health units, hospital based treatment should always be available, since severe relapses are better treated in inpatient setting.
\end{abstract}

Keywords: community-based services; hospitalizations; schizophrenia spectrum disorders; bipolar disorder; mobile mental health units; inpatient setting

\section{Introduction}

The reform of mental health services has started in many countries during the last decades. For those countries which are more economically developed there is a clear shift from asylum-based services towards the development of community-based services. There are some significant differences between asylum-based services and community-based services. Briefly, in the asylum-based services social therapeutic activities are minimal or non-existent, while at the same time rehabilitation activities are limited. On the other hand, social therapeutic and rehabilitation activities play an important role in the treatment plan of community-based services [1]. Furthermore, the community services work towards the creation of a social supportive system, something that is more difficult to happen in asylums. Finally, the asylum practices strengthen institutionalization and stigmatization, while the opposite happens with the community-based treatment. Community Mental Health Teams (CMHTs) are the key elements of community mental health services, representing the most simple model of providing community care, offering all kinds of interventions. A series of surveys and systematic reviews comparing CMHTs with other services based on hospitals, demonstrate significant advantages for the former, although it is not yet clear to what extent they improve the symptoms and the social functionality of the patients [2]. These benefits are related with the reduction of hospitalizations and relapses, as well as with the 
successful coverage of people's needs in remote and rural areas [3]. Community-based mental health services also act as a protective factor against involuntary hospitalizations [4] and improve the clinical picture of patients with schizophrenia spectrum disorders by reducing their positive and negative symptoms [5]. Furthermore it has been observed that through the cooperation with the multidisciplinary team of CMHTs, users of mental health services show greater adherence to treatment and they feel more satisfied, declaring that such services cover their needs more effectively [6].

Although community mental health services contribute to the treatment of mental illnesses [7], data are limited for the majority of European countries. To date, more evidence exists only for some high income countries [8,9]. Despite the limited number of reports on the effectiveness of CMHTs, they seem to ensure the continuity of mental care, especially for the treatment of psychotic disorders in the community [10].

According to a meta-analysis [11], CMHTs may affect positively not only hospitalizations, but also the financial burden both at family and at state level. In Greece, till now, only one study has been conducted [9] that highlights the beneficial role of Mobile Mental Health Units (the definition is given below), for the treatment of psychotic disorders in rural areas, by reducing both patients' admissions and length of hospitalizations.

The Greek governmental policy applying the principles of Psychiatric Reform (2716/99), has established a number of MMHUs in remote areas of the Greek territory, islands included $[12,13]$. Although all these units follow the rules of community psychiatry, there are great differences in the operational status in terms of staffing, organization of services etc. In the islands MMHUs are often residents' unique option in order to receive mental health care [10]. It has been argued that the existence of mobile mental health units offers a wealth of benefits to people who visit them. More specifically, the content of MMHU's actions has been linked to a significant contribution to the mentally ill person's health, for example through the ability of domiciliary visits as well as through telepsychiatry, in cases of remote areas [14,15]. Furthermore, MMHUs are responsible for the continuous prescription and supervision of patients' medication, since the appropriate pharmaceutical treatment is crucial for the mental health of these patients [10].

The Mobile Mental Health Unit of Kefalonia, Zakynthos and Ithaca (MMHU-KZI) is the only mobile unit in the Ionian Islands to date, providing psychosocial support and intervention both to people with psychiatric disorders and their families.

MMHU-KZI is oriented towards the continual service provision. The constant provision of mental care is regarded substantial for the optimal outcome of chronic mental disorders [16]. In this way it is easier to predict relapses and to intervene in time, since strong links develop between the personnel and the patients [17]. Recent data have demonstrated that the restriction of the continual mental health provision is associated with worse clinical condition for the psychotic patients [18].

Having examined a previous Greek study [9], we formulated some theoritical hypotheses. The hypotheses that we made are the following:

Hypothesis $\mathbf{1}$ (H1). The operation of the MMHU-KZI is related positively with the reduction of total hospital admissions (voluntary/involuntary) in patients with schizophrenia spectrum disorders and bipolar disorder.

Hypothesis $\mathbf{2}$ (H2). The operation of the MMHU-KZI is related positively with the reduction of involuntary hospital admissions in patients with schizophrenia spectrum disorders and bipolar disorder.

Hypothesis 3 (H3). The operation of the MMHU-KZI is related positively with the reduction of hospital stays (number of days) in patients with schizophrenia spectrum disorders and bipolar disorder.

The theoretical question is whether the operation of MMHU-KZI (details about the operation of the unit are mentioned in the follow section) has any effectiveness on the 
number of admissions and their duration for these patients. Consequently, the aim of the present study is to assess the changes in number of admissions, as well as changes in days of hospitalizations in patients with either schizophrenia spectrum disorders or bipolar disorder, treated by a MMHU in the islands of Kefalonia, Zakynthos and Ithaca. The objective of the present study is to assess the changes in number of admissions, as well as changes in days of hospitalization in patients with either schizophrenia spectrum disorders or bipolar disorder, treated by a MMHU in the islands of Kefalonia, Zakynthos and Ithaca.

\section{Materials and Methods}

\subsection{The Treatment Setting}

The MMHU-KZI started to operate in 2007. MMHU-KZI had been the only Mental Health Service in the islands of Kefalonia and Ithaka till 2008. It should be noted that these two islands have a large number of mountainous villages, some of which are particularly remote and difficult to access. The sample of the present study was derived exclusively from the island of Kefalonia.

Before the establishment of the MMHU-KZI, patients from Kefalonia who suffered from psychiatric disorders, had the choice either to visit the only private psychiatrist in the island or to travel long distances in the mainland to get to the nearer urban center (more often to Patra and Athens), at their own cost.

The operation of the unit is based on the principles of social and community psychiatry, giving priority to patients with severe and chronic mental disorders. The specific population shows greater needs and at the same time their care is much more challenging [10]. In addition, care for other categories of mentally ill patients is not excluded. The MMHU-KZI consists of a multidisciplinary team (adult psychiatrists, child and adolescent psychiatrists, psychologists, social workers, nurses). This multidisciplinary team delivers comprehensive and flexible care, covering many aspects of patients' lives (sessions, medication, domiciliary visits, mobilization actions, interconnection of the patient with the local community, job opportunities, housing etc). The delivery of care is continuous, depending on patient's needs. The patient is primarily assisted in the management of their symptoms, while the improvement of their functionality is the ultimate goal.

From the very beginning the MMHU-KZI faced serious challenges; how to ensure the enrollement of mental health providers (mainly of psychiatrists), to guarantee the necessary financial resources from the Greek government and also, to cope with the stigma of mental illness in the community. The administration of the MMHU-KZI gave from the begining priority to the training of the personnel based on the special features of local community, through the spirit of effective cooperation and team work (a key pillar of the unhindered operation of CMHUs). At the same time great attention was paid to ensure the easiest possible accessibility to the services, taking into account the diversity of citizens' needs. Psychiatric/psychological treatment and psychosocial support (through the spectrum of the holistic/biopsychosocial approach of mental illness), relapse prevention and crisis intervention are some of the MMHU-KZI main goals. At the same time, the interconnection and cooperation with the local agents are integral parts of unit's work, trying to form a network within the community, so as to cover effectively and with the shortest possible delay the needs of the residents of the Ionian islands.

\subsection{Study Design}

For the present study, data were collected from 239 patients' history cases with either schizophrenia spectrum disorders (F20-F29) or bipolar disorder (F31), according to the ICD-10 [19]. The sample of our study included patients who had been already in treatment with the MMHU-KZI (convenience sampling). Although, the MMHU-KZI is engaged with all people who seek psychosocial and psychiatric treatment, we give priority to patients with severe chronic psychiatric problems (such as psychosis and bipolar disorder), since these groups present higher percentages of relapses and hospitalizations. According to the 
literature psychotic patients [20,21] and bipolar patients [22-24] are in a large percentage poorly adherent with medications. This non-adherence leads very often to relapses [25] and chronicity of symptoms. The severity of psychotic and bipolar disorders and the vulnerability of these patients were the main reasons for focusing on them in our study.

The patients involved were in treatment from 2007 to 2021 in Argostoli-Kefalonia (MMHU-KZI) and information about the number and duration of their hospitalizations (before and after their cooperation with MMHU-KZI) was provided both by the patients themselves and their caregivers. It should be mentioned that patients involved gaved consensus for their participation, after having been informed about the exact scientific purpose of the study and the anonymity of the procedure. Last but not least, all patients were informed that no personal data would be published. The expediency and the methodology of our study were approved by the institutional board of the unit.

Treatment engagement was defined as the regular attendance to $80 \%$ (approximately) of the scheduled follow up appointments, according to the individual treatment plan. This was considered as a main predisposition for inclusion in the sample. From the initial sample, 110 cases met this criterion. Two cases with very frequent admissions (both had over $30 \mathrm{admissions}$ for the estimated period) were excluded, as they greatly differentiated from the average of the sample, causing a distortion of the statistical evaluation. We ended up with 108 cases, evaluated as appropriate for further study and analysis.

For the evaluation of the characteristics of the admissions before and after treatment engagement with the MMHU-KZI, a pre-post mirror comparison design was used. This means that for each patient comparison was made for the same time interval prior and after engagement to treatment with the MMHU-KZI, and not for the total hospitalizations that patients had in their history (i.e., if a patient had been for 5 years in the unit, we collected data for 5 years before patient's cooperation with the unit). The particular method has been already used in the recent research field [26].

\subsection{Statistical Design}

Data were analyzed using the SPSS program. Categorical variables were presented in frequencies and percentages while continuous variables were presented as mean and standard deviation (SD). In order to decide whether the variation in the number of hospitalizations (pre and post the engagement with the MMHU-KZI) was statistical significant, the Wilcoxon signed ranked test was applied. $p$-value $<0.05$ was considered statistically significant. The list with all the variables extracted from patients' records is available in Appendix A.

\section{Results}

Our final sample included 108 patients. 85 of them had been diagnosed with schizophrenia spectrum disorders (F20-F29), and 23 with bipolar disorder (F31).

The average age of patients was 52 years (SD 12.09), $49.1 \%$ were male and $50.9 \%$ female. Most were single (53.7\%), with a percentage of $19.4 \%$ being divorced or widowed. Most of them $(69.4 \%)$ lived with a caregiver, usually an elderly parent. In terms of their educational level, half of them $(50.0 \%)$ were high school graduates. The majority of patients $(50.9 \%)$ received a disability benefit, $22.2 \%$ received a state pension and only a small number of them $(9.3 \%)$ was working. Patients' characteristics are presented in Table 1. 
Table 1. Patients' demographic characteristics.

\begin{tabular}{ccc}
\hline & $\mathbf{N}=\mathbf{1 0 8}$ & \\
\hline Sex & Male & $53(49.1 \%)$ \\
& Female & $55(50.9 \%)$ \\
Age (mean, SD, years) & & $52(\mathrm{SD} 12.09)$ \\
Marital status & Not married & $58(53.7 \%)$ \\
& Married/Cohabited & $29(26.9 \%)$ \\
Caregiver & Divorced/Widowed & $21(19.4 \%)$ \\
& Living with a caregiver & $75(69.4 \%)$ \\
& Living alone & $21(19.4 \%)$ \\
Education & Living with other family members with & $12(11.2 \%)$ \\
& Severe Mental Illness (SMI) & $37(34.3 \%)$ \\
Employment & Primary & $54(50.0 \%)$ \\
& Secondary & $17(15.7 \%)$ \\
& Tertiary & $55(50.9 \%)$ \\
& Disability benefits & $24(22.2 \%)$ \\
& Pension due to aging & $19(17.6 \%)$ \\
& Unemployed & $10(9.3 \%)$ \\
\hline
\end{tabular}

All patients received psychiatric care (initial interview, prescription, sessions, follow up appointments etc), while very frequent psychosocial interventions were applied by the central reference person (care manager), and the specialized personnel of the unit. Psychoeducation for the caregivers (more often family members) was applied to the $93.5 \%$ of the sample. Domiciliary visits were carried out for $64.8 \%$ of the patients. Crisis intervention was made for $64 \%$ of the patients. Domiciliary care was carried out for $25 \%$ of the patients. The aim is for patients to comply with the medication. However, some of them are not capable to receive the medication on their own (there is often a lack of social context). Therefore, supervision is offered by the unit for the $54.6 \%$ of the sample. The psychosocial interventions from the MMHU-KZI are fully presented in Table 2.

Table 2. Psychosocial interventions of the MMHU-KZI.

\begin{tabular}{cc}
\hline Psychosocial Interventions & \% of Patients Who Received It \\
\hline Psychiatric support and pharmaceutical treatment & $100 \%$ \\
Psychosocial support from a care manager & $100 \%$ \\
Family psychoeducation & $93.5 \%$ \\
Home visits & $64.8 \%$ \\
Mobilization actions & $61.1 \%$ \\
Crisis intervention & $72.2 \%$ \\
Home care & $65.7 \%$ \\
Administration of medication & $25 \%$ \\
\hline
\end{tabular}

The average duration of illness was 23.4 years (SD 12.73). The mean number of hospitalizations during the illness was 1.63 (SD 1.99) (minimum number of hospitalizations: 0 -maximum number of hospitalizations: 9). The average duration of intervention from the MMHU-KZI was 6.73 years (SD 3.99). The patients included in the sample had 176 recorded hospitalizations, with $146(82.9 \%)$ of them being involuntary, while the remaining 30 were voluntary (17.1\%). Several important clinical features are presented in Table 3. 
Table 3. Patients' clinical characteristics.

\begin{tabular}{|c|c|c|}
\hline \multicolumn{3}{|c|}{$N=108$} \\
\hline Illness duration (mean, SD, years) & & $23.4(\mathrm{SD} 12.73)$ \\
\hline $\begin{array}{l}\text { Duration of follow-up } \\
\text { by the MMHU-KZI (mean, SD, years) }\end{array}$ & & 6.73 (SD 3.99) \\
\hline $\begin{array}{l}\text { Average number of hospitalizations } \\
\text { during the illness (mean, SD) }\end{array}$ & & 1.63 (SD 1.99) \\
\hline History of alcohol/substance abuse & & $32(29.6 \%)$ \\
\hline $\begin{array}{l}\text { Number of hospitalizations } \\
\text { during the illness }\end{array}$ & Involuntary & $146(82.9 \%)$ \\
\hline \multirow{3}{*}{$\begin{array}{l}\text { Number of involuntary hospitalizations } \\
\text { pre-post mirror interval }\end{array}$} & Voluntary & $30(17.1 \%)$ \\
\hline & $\begin{array}{l}\text { Before treatment engagement } \\
\text { with the MMHU-KZI }\end{array}$ & $51(67.1 \%)$ \\
\hline & $\begin{array}{l}\text { After treatment engagement } \\
\text { with the MMHU-KZI }\end{array}$ & $25(32.9 \%)$ \\
\hline \multirow[t]{2}{*}{$\begin{array}{l}\text { Mean days of hospitalizations } \\
\text { during the illness (mean, SD) }\end{array}$} & $\begin{array}{l}\text { Before treatment engagement } \\
\text { with the MMHU-KZI }\end{array}$ & $24(\mathrm{SD} 42.47)$ \\
\hline & $\begin{array}{l}\text { After treatment engagement } \\
\text { with the MMHU-KZI }\end{array}$ & 5 (SD 12.21) \\
\hline \multirow[t]{2}{*}{$\begin{array}{l}\text { Mean days of hospitalizations } \\
\text { pre-post mirror interval (mean, SD) }\end{array}$} & $\begin{array}{l}\text { Before treatment engagement } \\
\text { with the MMHU-KZI }\end{array}$ & 11 (SD 21.47) \\
\hline & $\begin{array}{l}\text { After treatment engagement } \\
\text { with the MMHU-KZI }\end{array}$ & 5 (SD 12.21) \\
\hline
\end{tabular}

Special attention should be paid to patients' treatment before their involvement with the MMHU-KZI; $50 \%(\mathrm{n}=54)$ of the patients had no treatment at all, while $47.2 \%(\mathrm{n}=51)$ of them received occasional treatment at a private setting without stable therapeutic monitoring or an integrated care plan. Only $2.8 \%(n=3)$ of the patients were engaged in a stable therapeutic setting before the engagement with the MMHU-KZI.

Another important figure refers to the source of reference; $38 \%(n=41)$ of the patients were referred to the MMHU-KZI by their family members, $28.7 \%(n=31)$ were referred to the MMHU-KZI by a Health Service, $13 \%(n=14)$ by a Welfare Service, $13.8 \%(n=15)$ were self-reported, while $6.5 \%(n=7)$ were reffered to the MMHU-KZI by other sources.

The Wilcoxon signed ranks test indicated:

- A $45.9 \%$ decrease in the number of hospital admissions after treatment engagement with the MMHU-KZI. The number of admissions was statistically lower in post engagement measurements than in pre-engagement measurements $(Z=-2.264, p=0.024)$.

- A reduction of $54.5 \%$ in days of hospitalization, after treatment engagement with the MMHU-KZI. Days of hospitalization per admission were statistically lower in measurements in post-engagement than in pre-engagement measurements $(Z=-2.009$, $p=0.045)$.

- Involuntary hospitalizations after MMHU-KZI involvement were decreased by $51 \%$. Involuntary admissions were found to be statistically lower after treatment engagement with the MMHU-KZI than before $(Z=-2.599, p=0.009)$.

\section{Discussion}

In the present study we noticed a significant reduction in hospital admissions in patients with either schizophrenia spectrum disorders or bipolar disorder, after being engaged in treatment with the MMHU-KZI. During the mean 6.73 years follow up period the percentage of the admissions was decreased by $45.9 \%$. Furthermore, for those patients hospitalized during the follow-up period, the duration of admissions was sustainably shorter, and specifically was reduced by $54.5 \%$. The reduction of involuntary admissions was also significant in the present study. After treatment engagement with the MMHU-KZI, involuntary admissions were decreased by $51 \%$. This finding is important, considering the negative impact of involuntary hospitalizations on patients [27]. MMHUs being close to the patients and their caregivers are able to recognize early signs of imminent relapses. 
This protective role of community mental health services against involuntary admissions has also been supported by other researchers in Greece [4].

The outcomes of our study agree with those of previous foreign and Greek studies. More specifically, a Greek study conducted in Athens demonstrated that community mental health facilities significantly decrease the number of hospitalizations and the duration of them [28]. Another recent study concerns the decrease of hospitalizations and length of hospital stay in patients with schizophrenia spectrum disorders treated by the Mobile Mental Health Unit of Ioannina and Thesprotia (MMHU I-T) [9]. Lykomitrou et al. (2021) proposed that the expansion of flexible and alternative community-based interventions, such as MMHUs, constitute a best practice both for obtaining higher clinical outcomes and for facing regional inefficiencies related to population's access to healthcare [29].

In addition, international data are inline with our outcomes, underlying the effectiveness regarding the hospital admissions [30], while other studies demonstrated improved clinical outcomes for patients with psychosis [31]. According to the cohraine review of Malone et al. (2007), the usefulness of community mental health team management for people with severe mental illnesses and personality disorders is not inferior to non-team standard care in any important respects and is superior in promoting greater acceptance of treatment. In addition the authors propose that it may be superior in reducing hospital admissions and avoiding death by suicide [30]. Van Citters and Bartels in their review found that home and community-based treatment of older adult psychiatric patients were associated with improved and longer maintained psychiatric status [32]. Finally, in a recent study, Castillo et al. (2019) demonstrated the effectiveness of community interventions for improving mental health [33].

During the study period, all patients participated, were only engaged with the MMHUKZI (and with no other mental health service provider). Therefore, the results of the present study are attributed to the MMHU-KZI actions, based on the principles of "community care".

The term "community care" means that the services are close to home. The geographical distance of mental health services from patients' residence, plays a pivotal role in the patients' decision to engage with these services. The closer the services are to patients the more likely for them and their families to make use of them and get involved in programs on a regular basis [34]. Although Kefalonia is a big mountainous island with several remote areas, it is a relatively small community in terms of population. One of the most important advantages of a CMHT or MMHT in a specific and relatively small community, is the ability of the mental health professionals to focus and cover the special needs of the mentally ill residents of this area. Even in countries with better mental health resources we find low coverage and poor focusing [2].

Another important issue, that the present study disclosed, was the insufficiency of the therapeutic treatment setting for the mentally ill in Kefalonia, Zakynthos and Ithaca before the establishment of the MMHU-KZI. This finding could be attributed to the absence of Mental Health Services in the area before the establishment of the MMHU and also to the fear of stigmatization on behalf of the patients and their families. Stigmatization against the mentally ill remains a major obstacle for them to seek psychological support by using mental health services [35]. MMHU-KZI has taken many actions in order to minimize such discriminations. Our modus operandi in MMHU-KZI is firmly oriented toward the continuity of care, a principle which is vital for the effective approach of chronic and serious mental illnesses [16]. Recent data support that the absence of continual provision of mental health services for the psychotic patients, leads to poorer outcomes [18].

Biopsychosocial model is the basic operational principle for MMHUs. According to the biopsychosocial model the patient should always be approached through the somatic, psychological, familiar and societal spectrum. Family focus therapy and psychoeducation are important components of a successful therapy and long-lasting remission. In one randomised controlled study, remitted bipolar patients whose relatives attended psychoeducation groups, had longer remissions than patients whose relatives did not attend similar sessions [36]. In a second study, bipolar patients whose caregivers attended 12-15 
family education sessions, showed significant decreases in symptoms of depression, especially when caregivers showed mood improvement as well [37]. Thus, adjunctive family interventions have the potential to lengthen periods of stability and alleviate residual symptoms [38]. Providing health services on a domiciliary basis is critical for MMHUs. In a recent study, regular visits at home are related with better treatment involvement for adult psychotic patients [39]. In addition, Okumura et al. (2018) concluded that follow up visits after hospitalization could be helpful for seriously affected patients, since they reduce the probability for subsequent readmission [40].

The present study demonstrated a noteworthy decrease in the number of hospital admissions and the duration of hospitalizations in patients with either schizophrenia spectrum disorders or bipolar disorder that cooperated with the MMHU-KZI. Although the community mental case model contributes to the wellbeing of the mentally ill, it is almost impossible to eliminate psychiatric admissions. Acute episodes and serious relapses could occasionally happen, regardless of our dedicated work, making an admission inevitable. Community care is not a panacea, therefore a comprehensive mental health system should include both community and hospital based care [41].

\subsection{Strengths and Limitations}

The sample of the study consisted of people with schizophrenia spectrum disorders and bipolar disorder, who received comprehensive care from the MMHU-KZI on a systematic basis. The results obtained, enrich the knowledge of the scientific community dealing with such issues in two ways. First, they reinforce the existing literature regarding the approach and treatment of people with psychosis and bipolar disorder and their families. Furthermore, secondly, they highlight the importance and effectiveness that characterize the Case Management model in practice, elements that are limited in the literature. In the present study the ability to examine the long-term effects of commitment to treatment, drove to the conclusion that the cooperation and commitment with the MMHU-KZI has affected considerably both the number of hospitalizations as well as the duration of the hospitalizations.

One of the major limitations of our study was that it was not possible to compare the Case Management model with any other approach and treatment for people with psychosis and bipolar disorder. Consequently, the absence of the control group prevent us from determining the course of the treatment outcomes of such patients under different treatment settings. However, it is important to emphasize, that our main goal was to demonstrate the improvement of the clinical condition of these patients, and not to compare different treatment approaches.

Finally, the results may not be generalized to other patients with same mental disorders, who live in different districts. This happens, as the MMHU-KZI is organised in order to cover the specific needs of the residents of the Ionian Islands. Although, all MMHUs in Greece operate emphasizing on the principles of social and community psychiatry, there are differences in their operational status. In order to extract safe conclusions about the effectiveness of MMHUs in Greece, the conduction of similar researches by different MMHUs would be useful.

\subsection{Implications for Care}

The MMHUs model seems to correspond to the needs of the residents in insular areas. Patients in such regions may be cut-off for other mental health services either due to the absence of such facilities in their districts, or due to socioeconomic issues [42].

Continuity of care is a basic pillar for the effective treatment of either schizophrenia spectrum disorders or bipolar disorder. However it is not always possible to ensure this continuity, especially when MMHUs operate in a context of significant "discontinuities". A potential problem is the lack of specialized personnel, especially psychiatrists, since working in remote and insular areas is not an alluring option for them. Another crucial factor is the difficulty to secure the necessary funding for the unhindered operation of 
MMHUs. As far as the MMHU-KZI is concerned, there was a long period of economic uncertainty and underfunding that created severe insecurity for the existence of the unit (specifically during the years 2011-2017). In addition, the economic crisis of the past decade has largely impeded the necessary financial support of health services by the Greek state [43]. Such adversities cause serious problems to the unhindered operation of MMHUs and demoralize the personnel.

The difficulties in receiving proper mental health care in rural and remote areas have been emphasized both in international and Greek literature [28]. Along with the aforementioned constraints, the non-existence of a psychiatric department in Kefalonia, Zakynthos and Ithaca is a harsh reality, differentiating the work load of the specific MMHU from other MMHUs in Greece. For example, in the case of hospitalizations the procedure becomes even more complicated and time consuming for the patients and their relatives. Furthermore, of course, bureaucracy and waste of time may be disastrous for the patient. Under these conditions, the personnel of MMHUs must always be alert for all possible adversities, deprived of the necessary interconnection and cooperation with a specialized psychiatric hospital department.

\section{Conclusions}

The findings of this study are in accordance with the findings of a previous Greek study [9]. The MMHU mediated treatment of patients with either schizophrenia spectrum disorders or bipolar disorder in remote areas may be both feasible and effective. MMHUs contribute to the decrease of hospitalizations and of their duration. Community-based mental health approach may be the most suitable model in providing reliable services to the severe psychologically affected residents in rural areas and islands of Greece. However, more studies are necessary in order to examine thoroughly all the parameters of this topic.

Author Contributions: Data curation I.D.; Project administration A.G.; Supervision A.G.; Writingoriginal draft A.G.; Writing-review \& editing I.T., Z.M. All authors have read and agreed to the published version of the manuscript.

Funding: The authors received no financial support for the research, authorship and/or publication of this article.

Institutional Review Board Statement: The study was conducted according to the guidelines of the Declaration of Helsinki, and approved by the Institutional Review Board METAVASI (protocol code 11B/2021, date of approval 26 May 2021).

Informed Consent Statement: The institutional board waived the need for informed consent, since it is not an interventional study.

Data Availability Statement: Research dataset may be provided if requested from METAVASI institution.

Conflicts of Interest: The authors declared no potential conflicts of interest with respect to the research, authorship and/or publication of this article.

\section{Abbreviations}

The following abbreviations are used in this manuscript:

MMHU-KZI Mobile Mental Health Unit of Kefalonia, Zakynthos \& Ithaca

\section{Appendix A. List of Variables Extracted from Patients' Records}

- Patients' demographic characteristics

$$
\begin{array}{ll}
\text { - } & \text { Sex } \\
\text { - } & \text { Age } \\
\text { - } & \text { Age group } \\
\text { - } & \text { Marital status } \\
\text { - } & \text { Educational level }
\end{array}
$$


- Employment status

- Caregiver

- Patients' clinical characteristics

- Diagnosis

- Diagnostic group

- Onset of disease

- Duration of disease

- History of alcohol - substance abuse

- Cooperation history with MMHU-KZI

- Reference

- Treatment before MMHU-KZI

- Date of monitoring start

- Date of monitoring interruption

- Monitoring period (years)

- Therapeutic continuity

- Psychosocial interventions

- Psychiatric support and pharmaceutical treatment

- Home visits

- Family psychoeducation

- Mobilization actions

- Interconnection with formal/informal networks

- Crisis intervention

- Home care

- Supervision/administration of medication

- Total Hospitalizations

- Total involuntary hospitalizations

- Total voluntary hospitalizations

- Total days of hospitalization before MMHU-KZI monitoring

- Total days of hospitalization during MMHU-KZI monitoring

- $\quad$ Total hospitalizations before MMHU-KZI monitoring

- Total hospitalizations after MMHU-KZI monitoring

- Hospitalizations for the pre - post MMHU-KZI monitoring mirror interval

- Hospitalizations before MMHU-KZI monitoring (Mirror interval)

- Hospitalizations after MMHU-KZI monitoring (Mirror interval)

- $\quad$ Days of hospitalization before MMHU-KZI monitoring (Mirror interval)

- Days of hospitalization during follow-up by MMHU-KZI monitoring (Mirror interval)

- Involuntary hospitalizations before MMHU-KZI monitoring (mirror interval)

- Involuntary hospitalizations after MMHU-KZI monitoring (mirror interval)

\section{References}

1. Madianos, M. Society and mental health-Volume two. In Community Psychiatry and Community Mental Hygiene; Kastaniotis: Athens, Greece, 1989.

2. Thornicroft, G.; Tansella, M. Better Mental Health Care, 1st ed.; Cambridge University Press: Cambridge, UK, 2008. [CrossRef]

3. Peritogiannis, V.; Mantas, C.; Alexiou, D.; Fotopoulou, V.; Mouka, V.; Hyphantis, T. The contribution of a mobile mental health unit in the promotion of primary mental health in rural areas in Greece: A two-year follow-up. Eur. Psychiatry 2011, 26, 425-427. [CrossRef] [PubMed]

4. Stylianidis, S.; Peppou, L.E.; Drakonakis, N.; Douzenis, A.; Panagou, A.; Tsikou, K.; Pantazi, A.; Rizavas, Y.; Saraceno, B. Mental health care in Athens: Are compulsory admissions in Greece a one-way road? Int. J. Law Psychiatry 2017, 52, 28-34. [CrossRef] [PubMed]

5. $\quad$ Chatterjee, S.; Naik, S.; John, S.; Dabholkar, H.; Balaji, M.; Koschorke, M.; Varghese, M.; Thara, R.; Weiss, H.A.; Williams, P.; et al. Effectiveness of a community-based intervention for people with schizophrenia and their caregivers in India (COPSI): A randomised controlled trial. Lancet 2014, 383, 1385-1394. [CrossRef] 
6. Sytema, S.; Micciolo, R.; Tansella, M. Continuity of care for patients with schizophrenia and related disorders: A comparative South-Verona and Groningen case-register study. Psychol. Med. 1997, 27, 1355-1362. [CrossRef] [PubMed]

7. Thornicroft, G.; Alem, A.; Dos Santos, R.A.; Barley, E.; Drake, R.E.; Gregorio, G.; Hanlon, C.; Ito, H.; Latimer, E.; Law, A.; et al. WPA guidance on steps, obstacles and mistakes to avoid in the implementation of community mental health care. World Psychiatry 2010, 9, 67-77. [CrossRef]

8. Semrau, M.; Barley, E.; Law, A.; Thornicroft, G. Lessons learned in developing community mental health care in Europe. World Psychiatry 2011, 10, 217-225. [CrossRef]

9. Peritogiannis, V.; Gioti, P.; Gogou, A.; Samakouri, M. Decrease of hospitalizations and length of hospital stay in patients with schizophrenia spectrum disorders treated in a community mental health service in rural Greece. Int. J. Soc. Psychiatry 2020, 66, 693-699. [CrossRef] [PubMed]

10. Peritogiannis, V.; Tatsioni, A.; Menti, N.; Grammeniati, A.; Fotopoulou, V.; Mavreas, V. Treatment engagement of psychotic patients with a mobile mental health unit in rural areas in Greece: A five-year study. Schizophr. Res. Treat. 2013, 1-6. [CrossRef]

11. Simmonds, S.; Coid, J.; Joseph, P.; Marriott, S.; Tyrer, P. Community mental health team management in severe mental illness: A systematic review. Br. J. Psychiatry 2001, 178, 497-502. [CrossRef]

12. Peritogiannis, V.; Mavreas, V. Community mental health teams in Greece: The paradigm of mobile mental health units. Arch. Hell. Med. 2014, 31, 71-76.

13. Stylianidis, S.; Pantelidou, S.; Poulios, A.; Lavdas, M.; Lamnidis, N. Mobile mental health units on the Islands: The experience of cyclades. In Social and Community Psychiatry, 1st ed.; Springer International Publishing: Athens, Greece, 2016 ; pp. 167-191. [CrossRef]

14. Peritogiannis, V. Mental healthcare in rural Greece: An overview. Dialogues Clin. Neurosci. Ment. Health 2019, 2, 155-162. [CrossRef]

15. Peritogiannis, V.; Grammeniati, A.; Gogou, A.; Gioti, P.; Mavreas, V. Very long-term outcome of community-dwelling patients with schizophrenia spectrum disorders in rural Greece. J. Nerv. Ment. Dis. 2019, 207, 1012-1018. [CrossRef]

16. Burns, T.; Catty, J.; White, S.; Clement, S.; Ellis, G.; Jones, I.R.; Lissouba, P.; McLaren, S.; Rose, D.; Wykes, T. Continuity of care in mental health: Understanding and measuring a complex phenomenon. Psychol. Med. 2009, 39, 313-323. [CrossRef] [PubMed]

17. Henderson, C.; Flood, C.; Leese, M.; Thornicroft, G.; Sutherby, K.; Szmukler, G. Effect of joint crisis plans on use of compulsory treatment in psychiatry: Single blind randomised controlled trial. BMJ 2004, 329, 136. [CrossRef] [PubMed]

18. Macdonald, A.; Adamis, D.; Craig, T.; Murray, R. Continuity of care and clinical outcomes in the community for people with severe mental illness. Br. J. Psychiatry 2019, 214, 273-278. [CrossRef] [PubMed]

19. World Health Organization. The ICD-10 Classification of Mental and Behavioural Disorders: Clinical Descriptions and Diagnostic Guidelines, 1st ed.; World Health Organization: Geneva, Switzerland, 1992.

20. Acosta, F.; Hernández, J.; Pereira, J.; Herrera, J.; Rodríguez, C. Medication adherence in schizophrenia. World J. Psychiatry 2012, 2, 74-82. [CrossRef]

21. Higashi, K.; Medic, G.; Littlewood, K.; Diez, T.; Granström, O.; De Hert, M. Medication adherence in schizophrenia: Factors influencing adherence and consequences of nonadherence, a systematic literature review. Ther. Adv. Psychopharmacol. 2013, 3, 200-218. [CrossRef]

22. Gaudiano, B.; Weinstock, L.; Miller, I. Improving Treatment Adherence in Bipolar Disorder: A Review of Current Psychosocial Treatment Efficacy and Recommendations for Future Treatment Development. Behav. Modif. 2008, 32, 267-301. [CrossRef]

23. Chakrabarti, S. Treatment-adherence in bipolar disorder: A patient-centred approach. World J. Psychiatry 2016, 6, 399-409. [CrossRef]

24. Jawad, I.; Watson, S.; Haddad, P.; Talbot, P.; McAllister-Williams, H. Medication nonadherence in bipolar disorder: A narrative review. Ther. Adv. Psychopharmacol. 2018, 8, 349-363. [CrossRef]

25. Emsley, R. Non-adherence and its consequences: Understanding the nature of relapse. World Psychiatry 2013, 12, 234-235. [CrossRef] [PubMed]

26. Schöttle, D.; Ruppelt, F.; Schimmelmann, B.G.; Karow, A.; Bussopulos, A.; Gallinat, J.; Wiedermann, K.; Luedecke, D.; Rohenkohl, A.C.; Huber, C.G.; et al. Reduction of Involuntary Admissions in Patients with Severe Psychotic Disorders Treated in the ACCESS Integrated Care Model Including Therapeutic Assertive Community Treatment. Front. Psychiatry 2019, 10, 736. [CrossRef] [PubMed]

27. Rusch, N.; Muller, M.; Lay, B.; Corrigan, P.W.; Zahn, R.; Schonenberger, T.; Bleiker, M.; Lengler, S.; Blank, C.; Rossler, W. Emotional reactions to involuntary psychiatric hospitalization and stigma-related stress among people with mental illness. Eur. Arch. Psychiatry Clin. Neurosci. 2014, 264, 35-43. [CrossRef] [PubMed]

28. Madianos, M.G.; Economou, M. The Impact of a Community Mental Health Center on Psychiatric Hospitalizations in Two Athens Areas. Community Ment. Health J. 1999, 35, 313-323. [CrossRef] [PubMed]

29. Lykomitrou, A.; Stylianidis, S.; Geitona, M.; Pantelidou, S.; Souliotis, K. Assessment of the Mobile Mental Health Units' effectiveness in Cyclades islands. Psychiatriki 2021, 32, 199-207. [CrossRef]

30. Malone, D.; Marriott, S.; Newton-Howes, G.; Simmonds, S.; Tyrer, P. Community mental health teams (CMHTs) for people with severe mental illnesses and disordered personality. Cochrane Database Syst. Rev. 2007, 3. [CrossRef] [PubMed]

31. Thornicroft, G.; Wykes, T.; Holloway, F.; Johnson, S.; Szmuckler, G. From efficacy to effectiveness in community mental health services. Br. J. Psychiatry 1998, 173, 423-427. [CrossRef] 
32. Van Citters, A.; Bartels, S. A Systematic Review of the Effectiveness of Community-Based Mental Health Outreach Services for Older Adults. Psychiatr. Serv. 2004, 55, 1237-1249.. [CrossRef]

33. Castillo, E.; Ijadi-Maghsoodi, R.; Shadravan, S.; Moore, E.; Mensah, M., III; Docherty, M.; Nunez, M.; Barcelo, N.; Goodsmith, N.; Halpin, L.E.; et al. Community Interventions to Promote Mental Health and Social Equity. Curr. Psychiatry Rep. $2019,21,35$. [CrossRef]

34. Zulian, G.; Donisi, V.; Secco, G.; Pertile, R.; Tansella, M.; Amaddeo, F. How are caseload and service utilisation of psychiatric services influenced by distance? A geographical approach to the study of community-based mental health services. Soc. Psychiatry Psychiatr. Epidemiol. 2011, 46, 881-891. [CrossRef]

35. Zartaloudi, A.; Madianos, M. Stigma related to help-seeking from a mental health professional. Health Sci. J. 2010, 4, 77-83.

36. Reinares, M.; Colom, F.; Sanchez-Moreno, J.; Torrent, C.; Martinez-Aran, A.; Comes, M.; Goikolea, J.M.; Benabarre, A.; Salamero, M.; Vieta, E. Impact of caregiver group psychoeducation on the course and outcome of bipolar patients in remission: A randomized controlled trial. Bipolar Disord. 2008, 10, 511-519 [CrossRef]

37. Perlick, D.A.; Miklowitz, D.J.; Lopez, N.; Chou, J.; Kalvin, C.; Adzhiashvili, V.; Aronson, A. Family-focused treatment for caregivers of patients with bipolar disorder. Bipolar Disord. 2010, 12, 627-637. [CrossRef] [PubMed]

38. Geddes, J.R.; Miklowitz, D.J. Treatment of bipolar disorder. Lancet 2013, 381, 1672-1682. [CrossRef]

39. Peritogiannis, V.; Manthopoulou, T.; Gogou, A.; Mavreas, V. Mental Healthcare Delivery in Rural Greece: A 10-year Account of a Mobile Mental Health Unit. J. Neurosci. Rural. Pract. 2017, 8, 556-561. [CrossRef]

40. Okumura, Y.; Sugiyama, N.; Noda, T. Timely follow-up visits after psychiatric hospitalization and readmission in schizophrenia and bipolar disorder in Japan. Psychiatry Res. 2018, 270, 490-495. [CrossRef]

41. Thornicroft, G.; Tansella, M. The balanced care model for global mental health. Psychol. Med. 2013, 43, 849-863. [CrossRef]

42. Thornicroft, G.; Semrau, M.; Alen, A.; Drake, R.E.; Ito, H.; Mari, J.; McGeorge, P.; Tara, R. Community Mental Health: Putting Policy into Practice Globally; Wiley-Blackwell: New York, NY, USA, 2011.

43. Giannakopoulos, G.; Anagnostopoulos, D.C. Psychiatric reform in Greece: An overview. BJPsych Bull. 2016, 40, 326-328. [CrossRef] 